\title{
Managing the Creative Process within Graphic Design firms: A Literature Review
}

\author{
JESSICA JACOBS ${ }^{1}$ \\ 1. Columbia College Chicago, Chicago, IL, USA
}

SUGGESTED CITATION: Jacobs, J. “Managing the Creative Process Within Graphic Design Firms: A Literature Review."

Dialectic, 1.2 (2017): pgs. 155-178. DOI: http://dx.doi.org/10.3998/dialectic.14932326.0001.208

\section{Abstract}

This literature review examines an array of research that interrogates how the creative process in graphic design firms can be most successfully managed. There is substantial documentation of research on various approaches that have the potential to foster a creative climate in a professional setting, as well as documentation of research about what types of activities and sequences of activities constitute and inform creative processes. However, there appears to be a paucity of research undertaken that has specifically addressed how graphic designers working within professional design studios or larger, project-based enterprises and collaboratives formulate and manage (or are directed to manage) their respective creative processes. To this end, this paper attempts to answer the call from the editors of Dialectic stated in Issue 1 of the journal, which challenges design educators to "fill in the blanks" of design education. ${ }^{1}$ Specifically, the "blanks" addressed in this paper revolve around the extent to which design educators prepare students for professional practice by familiarizing them with at least some viable means of not just engaging in, but managing, creative processes.

A key question for contemporary graphic design educators arises from this type of inquiry: how should the management of the creative processes taught to students be aligned or not aligned with the way creative processes are managed by graphic design professionals in their respective working environments? In other words, how should we differentiate the reality of the professional practice of creative processes and the ideal of how they are presented and taught in academic environments? Based on the knowledge cultivated by exploring the depths of this question in a review of literature, the relevant focus of inquiry shifts toward examining how design educators might effectively translate and incorporate management practices into curricular and pedagogic structures that could help better prepare students to effectively and successfully enter and then sustain careers within the contemporary design workplace. 
Owens, K. M. \& Gibson, M. R. "It's time to stir the pot..." Dialectic, 1.1 (2016): pgs. 5-8. 


\title{
Managing the Creative Process within Graphic Design Firms:
}

\author{
A Literature Review
}

JESSICA JACOBS

\section{Introduction}

This survey paper reviews the literature on the structure, practices, and management of creative processes within select graphic design firms so that design educators can better prepare their students for the day-to-day reality of working within professional design environments. The initial inquiry that guided this endeavor focused on existing academic research that critically examined general management approaches and practices operated within professional graphic design firms and, more specifically, on the management of the creative processes that must effectively transpire within them so they can achieve some measure of financial and critical success. However, while the foci of design research has expanded broadly in the past four-plus decades, the investigation and critical interrogation of the professional practices of graphic designers has remained somewhat limited, as indicated by the lack of doctoral degrees and research agendas in graphic design. ${ }^{2}$ Indeed, as this dearth of research became apparent as the author's initial research progressed, the scope of inquiry was expanded to include research that examined management approaches and practices as they affected creative processes across other design disciplines, such as product design and architecture. This survey includes information

Griffin, D. "Doctoral Education in (Graphic) Design." Dialectic, 1.1 (2016): pgs. 135-154. gleaned from single-author and edited volumes on design management, a small grouping of ethnographic studies that look specifically at how graphic designers work within firms in the US, Canada, and the UK, and a synopsis of more 
generalized research on managing creativity in the creative industries.

In analyzing this literature, the following predominant recurring themes, or frameworks, emerged:

- those that involved elucidating design processes as a means to understand design management;

- those that involved examining various types of managerial approaches in professional design settings, including the need to balance interventions in the creative process versus allowing designers to work more autonomously;

- those that involved examining how constructed and embodied knowledge is created within design studios, including the development of shared vocabularies and collaborative relationships among design team members;

- those that involved examining how the insertion of constraints imposed by business-focused interests affects constraints imposed by design-focused interests, and vice-versa, within and around creative processes operating within various types of professional design settings.

This review also investigates how and why the implications of these research themes can be applied to graphic design pedagogy. Articulated in the form of a synoptic question, it is posed as follows: how might a discussion about the management of the creative process in professional graphic design settings most effectively inform our curricular and pedagogical approaches? This paper will discuss how much we might or might not align these "real world" practices with how the approaches and practices we formulate and engage in to educate

\section{3}

Jacobs, J. "Teaching the Business of Design Across Disciplines." The International Journal of Design Education, 10.2 (2016): pgs. 19-29.; Grant, D. "Special Business Degrees Mark Shift from Making Art to Managing It." The Chronicle of Higher Education, 9 February, 2011. Online. Available at: http://www.chronicle. com/blogs/arts/special-businessdegrees-mark-shift-from-makingart-to-managing-it/28613 (Accessed June 28,2017$)$. our students to be successful in the workplace.

In addition to purposefully attempting to better prepare graphic design students to embark on and sustain successful careers, this inquiry is located within the logistical and pedagocical context of an increase in undergraduate degrees offered in design management in American university-level design programs. Once almost exclusively the province of graduate programs, more design management degrees are now offered in the us at the undergraduate level, although there are still only about a dozen of these operating around the country. ${ }^{3}$ Design management is defined differently in various texts, but can 
4

"What is Design Management?" Design Management Institute. Online. Available at: http://www. dmi.org/?What_is_Design_Manag (Accessed June 24, 2017). be generally understood to be a discipline/profession that encompasses, "the ongoing processes, business decisions, and strategies that enable the development of designed products, services, communications, and environments." 4

While not exclusively the focus of this review, future research could and should synthesize the pedagogical implications articulated in this review for both design management and graphic design students.

\section{Crearivity}

Prior to examining the specific literature on creative design management within graphic design firms, it is useful to formulate a working definition for what constitutes the creative process through a brief examination of scholarship on creativity and its management within the creative industries (specifically, those involving design, which delimits this grouping from those that might also include music, film, radio, television and theatre). In the context of this examination, an individual designer's or design team's ability to engage in the creative process means that they can effectively immerse themselves in the following kinds of activities:

- Being actively and persistently involved in some type of an inventive or innovative process that may not yield predictable results;

- Being emotionally involved in the sustenance of an endeavor that yields a variety of results;

- Being able to offer broadly informed, critical analysis, and assessment as a given project evolves;

- Being able to iteratively develop a broad range of original ideas within the context of a given project's stated parameters or criteria;

- Being able to generate ideas and concepts that add value to a particular undertaking or initiative;

- Being able to generate viable and tangible results to a given creative challenge in a set span of time;

- Being able to operate well-cultivated understandings within a given domain of knowledge;

- Being comfortable with uncertain or ill-defined aspects of given challenges or projects;

- Being able to work spontaneously and to make effective use of subconscious processes; 
Moultrie, J. \& Young, A. “Explora-

tory Study of Organizational Creativity in Creative Organizations." Creativity and Innovation Management, 18.4, (2009): pgs. 299-314.

\section{6}

Amabile, T. Creativity in Context: Update to the Social Psychology of Creativity. Boulder, CO, USA: Westview Press, 1996.

\section{7}

Ekvall, G. “Organizational Climate for Creativity and Innovation."

European Journal of Work and Organizational Psychology, 5.1, (1996):

pgs. 105-123.

8 Ibid., 105 9

Moultrie \& Young, “Exploratory Study of Organizational Creativity in Creative Organizations," 309; Ekvall, “Organizational Climate for Creativity and Innovation," 107-108.
- Being able to effectively draw from a broadly informed, deeply plumbed intellect;

- Being able to work independently without overt, external need for encouragement;

- Being able to engage in effective social interactions and communications of the types that sometimes require a high level of emotional intelligence.

While not all of these activities are specifically addressed in this review, we can understand them to constitute at least some aspects of the creative processes operated by many of the types of professional graphic design organizations within which students will potentially attempt to sustain their careers.

\section{Examining Factors That Contribute to the Maintenenance of a "Creative Climate" in a Professional Design Organization}

One of the few scholarly articles that interrogates how creative processes are managed specifically in graphic design firms is Moultrie and Young's "Exploratory Study of Organizational Creativity in Creative Organizations." ${ }^{5}$ This study examines the management of the creative practices operated by branding/graphic design firms, as well as architecture and industrial design firms. Working from the models of creativity developed by psychology researchers Amabile ${ }^{6}$ and Ekvall, ${ }^{7}$ the authors developed questionnaires and conducted interviews with professional designers that surveyed their respective firms' creative effectiveness. In particular, factors that were identified as positively contributing to what respondents referred to as the maintenance of a 'creative climate' were explored. As defined by Ekvall, the climate metaphor refers to the combination of feelings, attitudes, and behaviors that characterize life in an organization, independent of what participants in the organization may say or believe. ${ }^{8}$ These factors then influence organizational conditions that stimulate or hamper creativity, leading to an overall description of an organization's 'creative climate.' Moultrie and Young modified Ekvall's creative climate criteria to develop their own list, which includes the following: ${ }^{9}$

- Idea time (how much time people had to develop concepts)

- Risk-taking (the general tolerance for uncertainty, especially with regard to project-based outcomes, in the organization) 
- Challenge (the involvement of the employees in identifying and framing the operations and goals of the organization)

- Freedom (the relative tolerance of independence in the day-to-day behavior of individuals and teams)

- Idea support (how openly ideas are received in general, and whether they are received in an attentive and supportive way)

- Conflicts (the maintenance of a social atmosphere, or office culture, within which personal and emotional tensions can be easily and effectively addressed and resolved)

- Debates (the maintenance of a social atmosphere, or office culture, within which clashes between people and the ideas they generate and either support or inhibit can be easily and effectively addressed and resolved)

- Playfulness/humor (the maintenance of a relaxed, spontaneous social and cultural atmosphere)

- Trust/openness (the maintenance of a social atmosphere, or office culture, that nutures emotional security in relationships between collaborators/staff)

- Dynamism/liveliness (the general eventfulness of day-to-day life in an organization)

Overall, the authors felt that several 'creative climate' criteria (conflicts, idea time, team selection, access to funds, management systems, and training) were less important in creative firms than in non-creative firms, suggesting a hierarchy of factors variable by industry and management approach. ${ }^{10}$ The function of these criteria in professional design settings will be critically explored in the following four-part discussion, the subsequent sections of which are titled:

“Exploring Some Key Facets of Design Management;"

"Investigating Managerial Qualities;"

"Analyzing How Design Processes Are Affected by the Environment Within Which They Occur;" and "Constraints."

10

Moultrie \& Young, “Exploratory

Study of Organizational Creativity

in Creative Organizations," 309.
The content of each of these discussion sections investigates how design managers can foster or inhibit the maintenance of a creative climate in a professional design environment. 


\section{Exploring Some Key Facets of Design Management}

In examining the management of creativity and the creative process in graphic design firms, the texts on design management which synthesize previous liter-

11

Best, K. Design Management: Managing Design Strategy, Process and Implementation. London, UK: Bloomsbury, 2015. 12

Best, K. The Fundamentals of Design Management. Lausanne, Switzerland: AVA Publishing, 2010.

13

Cooper, R., Junginger, S., \& Lockwood, T., eds. The Handbook of Design Management. London, UK: Bloomsbury, 2013.

14

Borja de Mozota, B. Design Management: Using Design to Build Brand Value and Corporate Innovation. New York, NY, USA: Allworth Press, 2003.

15

Oakley, M., Borja de Mozota, B. \& Clipson C., eds. Design Management:

A Handbook of Issues and Methods. Cambridge, MA, USA: Blackwell Reference, 1990.

\section{6}

Von Stamm, B. Managing Innovation, Design and Creativity. West Sussex, UK: John Wiley \& Sons, 2008; Borja de Mozota, Design Management: Using Design to Build Brand Value and Corporate Innovation; Oakley et al., Design Management: A Handbook of Issues and Methods; Cooper et al., The Handbook of Design Management.

\section{7}

Borja de Mozota, Design Management: Using Design to Build Brand Value and Corporate Innovation, 15.

18 Ibid. , 18 .

19 Ibid., 14 . ature and research on design management practices were reviewed first. The most prominent examples published since 2000 include single author texts and edited volumes comprised of work from multiple authors such as Design Management: Managing Design Strategy, Process and Implementation, ${ }^{11}$ The Fundamentals of Design Management, ${ }^{12}$ The Handbook of Design Management, ${ }^{13}$ and Design Management: Using Design to Build Brand Value and Corporate Innovation, ${ }^{14}$ as well as Oakley's edited volume from 1990, Design Management: A Handbook of Issues and Methods. ${ }^{15}$ These texts are inclusive of many design disciplines, including environmental design, product design (including automotive and furniture), package design, architecture, and graphic design. ${ }^{16}$ The authors of these texts do not specifically address variations in the management of these different design disciplines.

\section{Examining the Design Management of Creativity}

Within these design management texts, it is enlightening to examine examine how the creative process has been described. Borja de Mozota outlines the stages of the design process as: investigation, research, exploration, development, realization, and evaluation. ${ }^{17}$ She points out that the creative process involves many areas of management decision-making, such as market research, marketing strategy, branding, engineering, new product development, production planning, distribution, and corporate communication. ${ }^{18}$ Most interestingly, she notes the following in her discussion of design as a creative process (emphasis mine):

Whether analytical, iterative, or visionary, the design process follows different phases... These creative phases are identical no matter what the design discipline or design project is. These phases are also similar to the creative processes existing in other cultural fields. ${ }^{19}$

If the phases are identical across design disciplines, a question arises regarding how similar or different the management of these phases are across the design disciplines. As we examine this question, it is helpful to look to ethnographic studies to see if, in fact, the management of the creative phases of graphic 
20

Moultrie \& Young, “Exploratory

Study of Organizational Creativity

in Creative Organizations," 306.

21

Banks, M., Calvey, D., Owen, J., \&

Russell, D. "Where the Art Is:

Defining and Managing Creativity

in New Media SMEs." Creativity

and Innovation Management, 11.4

(2002): pgs. 255-264.

22

Moultrie \& Young, “Exploratory

Study of Organizational Creativity

in Creative Organizations."

23

Borja de Mozota, Design Management:

Using Design to Build Brand Value

and Corporate Innovation, 20. design processes are similar to the management of those that guide creative processes in other design professions.

In one such study, "Exploratory Study of Organizational Creativity in Creative Organizations," Moultrie and Young determined (through surveys and interviews) that architecture and product design firms placed more emphasis on utilizing management systems than did branding/graphic design firms. ${ }^{20}$ The authors speculated that a possible reason for this is tied to the fact that branding/graphic design firms tend to be smaller in size (they did not identify how or at what scale) than architecture and product design firms, and therefore do not require the operation of management systems to facilitate the strategic and tactical operations of their employees and employee teams. ${ }^{21}$ Examining the 'creative climate' factor of idea time revealed another difference between how respondents from different types of design firms described their means for managing creative processes. (Idea time refers to the literal span of time which an individual or team is generally given to develop creative ideas or concepts.) This factor was deemed to be an under-performer in many of the branding/graphic design firms that were examined, meaning respondents in those firms reported less satisfaction with the amount of time they were usually given to engage in processes that involved creative ideation. ${ }^{22}$ This study indicates that there are, in fact, some differences between how the creative process takes shape in graphic design firms when compared with how this occurs in other design disciplines such as architecture and product design. The revelations of this study suggest that graphic design students must be taught - in the learning experiences that constitute their coursework - to be cognizant of the tight and often variable turnaround times commonly allotted in professional environments to processes that involve idea generation or conceptual development. More simply put, the revelations of this study also suggest that emerging graphic designers need to become practiced at developing viable solutions, or designed outcomes, quickly.

As a whole, examining the structure and content of the design management texts addressed in this review reveals that, at least in the opinion of these authors, the creative process is embedded within more complex and organizationally encompassing business processes such as strategy and operations. Indeed, as Borja de Mozota opines, design is fundamentally both a creative and a management process. ${ }^{23}$ This declaration begs this question: are we embedding enough of the learning experiences that constitute our graphic design curricula with the study of, or immersion into, at least basic management

\section{3}


strategies and functions? As Meredith Davis noted in her essay Raising the Bar for Higher Education, "It makes little sense...to continue to educate tens of thousands of students each year solely in the design and production of beautiful form." ${ }^{24}$ Instead, she called for design educators to design and facilitate curricula that challenged students enrolled in them to create work that addressed real-world contextual factors that accounted for managerial, social, and cultural perspectives. ${ }^{25}$ As educators, the onus has been placed upon us to determine how effectively we have responded to this call, which Davis originally sounded 2005 , by assessing just how well-prepared our students are to enter and then sustain careers in the ever-diversifying profession of graphic design. Students who emerge from design school without significant knowledge of how management strategies and tactics, cultural imperatives, and social agendas affect creative processes in professional settings are ill-equipped to succeed within them. Possessing mere formal design abilities ("having a good portfolio of work") has been repeatedly shown to be insufficient to sustain the career of an emerging graphic designer in the 12 years that have passed since Davis originally issued this challenge.

\section{Investigating Managerial Qualities}

One of the most consistent themes that arose from the review of these texts is that successfully planned and operationalized creative processes - the types that yield useful and desirable outcomes in professional design settings-require the consistent assertion of strong managerial qualities combined with well-reasoned, broadly informed managerial behaviors. In The Fundamentals of Design Management ${ }^{26}$ and Design Management: Using Design to Build Brand Value and Corporate Innovation, ${ }^{27}$ the authors outline the many variables that contribute to success in the business of design. In doing so, they emphasize the experience, expertise, and qualities of an effective design manager. Much of what Best describes as the functions of an effective design manager equate with those of an effective project manager. This is someone who discovers or invents ways to intelligently plan and coordinate available resources to deliver a successful project - again, one that yields a useful and desirable outcome-on time and within budget without losing sight of the client's or facilitating organization's strategic business goals. ${ }^{28}$ Best's text, much like many of its counterparts, describes the process of design and the functions of design management, but fails to delve into specifics about how a manager might most efficiently and effectively implement these best practices, much less how they might vary 
29

Ibid., 134 .

30

Ibid.

31

Borja de Mozota, Design Management: Using Design to Build Brand Value and Corporate Innovation, 216.

32

Borja de Mozota, Design Management: Using Design to Build Brand Value and Corporate Innovation, 217.

when operated within a specific design discipline. While this connection is not directly made by these authors, a synoptic analysis of their work suggests that linking the ideas pertinent to design management they promote to ethnographically framed and guided design processes can help students emerge into the marketplace better equipped to make meaningful contributions to a contemporary graphic design firm. In this context, "ethnographically framed and guided design processes" require designers to study and interact with those who will comprise their audiences and users as they live and work in their own environments, and then use the knowledge they glean from this to inform their design decision-making.

Many of the reviewed texts also highlight the importance of assembling teams that function effectively on a day-to-day basis and over time, and, part and parcel to this, how a design manager must work thoughtfully and diligently to identify and fulfill required roles and provide necessary resources. "Getting the most from creative teams relies on good communication, delegation and leadership skills, and valuing and respecting the different styles, approaches, talents and skills of all team members." ${ }^{29}$ Best notes that the 'chemistry' inherent in and the informal interactions within the team are of great import. ${ }^{30}$ Borja de Mozota illustrates the leadership abilities required of an effective manager, which include assembling a team of diverse specialists across a broad-range of competencies. These include design and technical skills, and are augmented by the possession of well-honed interpersonal skills. Accrued experience in and around a given type of design challenge also count for a lot, as does the marriage of an individual's personality with others that might constitute a team. ${ }^{31}$ These understandings needs to be shared in contemporary graphic design classrooms in ways that allow students to construct knowledge about what traits, proclivities and sensibilities - which should not be equated with formal skills - design managers now look for in emerging designers. Borja de Mozota outlines this in her "competency model for designers," which focuses on design abilities, business knowledge and awareness, personal qualities, and interpersonal skills. ${ }^{32}$ A key takeaway from an analysis of her work and how it applies to our charges as university-level graphic design educators is that the breadth of what we now teach must expand to encompass far more than the cultivation of our students' aesthetic abilities.

\section{Comparing Managers Who Have Accrued Design Experience with Managers Who Have Not}

\section{5}


Another guiding theme that emerged from almost all of the reviewed literature centered on the need to combine knowledge gained from engaging in design processes with understandings informed by having engaged in management processes and then using these to actively manage creative processes. Deeper analysis of this work reveals a sharp dichotomy in the authors' descriptions of management practices in design firms wherein the manager of creative processes is a designer and ones where this manager is not. While the creative processes (as described by Borja de Mozota) might be the same, or at least be described in similar terms, the management of these processes does not appear to be.

On one end of the spectrum, design management texts that target more hierarchical sub-disciplines within design (such as product design and industrial design) highlight the differences between the practices of managers and designers, and suggest ways that they can better understand each other and work together. In this literature, there is an emphasis on the conflict and/or confusion that may arise when managers are not designers or lack design experience. ${ }^{33}$ Walker highlights these differences in his detailed list of "manager-designer polarities" that contrasts characteristics of aims, focus, education, thinking styles, behavior, and culture. ${ }^{34}$ In light of this, it would be useful for design educators to call students' attention to this chart, and for them to understand the ramifications of charting a career path that involves them eventually not working for a designer, or a manager with design experience, but working instead for a manager whose practices are informed by knowledge from outside design. Students need to understand the implications this type of work situation could have on their ability to engage in what they have come to understand as the design process, as well as the types of prod-

33

Von Stamm, Managing Innovation, Design and Creativity, 13.

34

Walker, D. "Managers and Designers: Two Tribes at War?" in Design Management, ed. Oakley, M., Borja de Mozota, B. \& Clipson, C. (Cambridge, MA, USA: Blackwell Reference, 1990), pgs. 145-154. 35 Banks et al., "Where the Art Is: Defining and Managing Creativity in New Media SMEs." uct - or procedure, or way(s) of doing or making — that might emerge from it in this context. This is also an arena in design education that affords educators opportunities to teach how to handle potential managerial conflict effectively and professionally.

In contrast at the other end of the spectrum, ethnographic studies that focus on examining the cultures of professional graphic design firms do not reveal this gap in perception among design staffs between "manager" and "designer," or, when they do, they clearly reveal that designers prefer to work in situations wherein a manager is also a designer, or has accrued significant design experience. In "Where the Art is: Defining and Managing Creativity in New Media SMEs," ${ }^{35}$ the authors investigated (via survey instruments) how 
36

Ibid., 260

37

Murray, D. "An Ethnographic Study of Graphic Designers," in Proceedings of the Third European Conference on Computer-Supported Cooperative Work, 13-17 September 1993, Milan, Italy, Dordrecht, The Netherlands: Kluwer Academic Publishers, 1993: pgs. 295-309; Von Stamm, Managing Innovation, Design and Creativity.

\section{8}

Oakley et al., Design Management: A Handbook of Issues and Methods, 17; Julier, G. Economies of Design, London, UK: Sage Publications, 2017,40

managers define, value, and manage creativity in graphic design, advertising, and marketing firms. The authors note that if a manager sees himself/herself as a designer, he/she will value creativity more as a key part of the firm's identity and value proposition. ${ }^{36}$ Similar conclusions were drawn in a study titled "Ethnographic Study of Graphic Designers," a paper that focused (via close observation) on in-house design teams at a medium-sized, American promotional products company. Within this study, designers were found to respect the input of a manager who was or currently is a designer versus one who is not or has not been one. ${ }^{37}$ In these particular studies, designers have been shown to feel that in order to truly understand the 'fuzzy' nature of creative problem definition, framing, and iterative development toward some type of solution or outcome, one must have accrued a significant amount of professional design experience.

Because of these dichotomies, further questioning and future research is required that examines how various managerial styles, trust, collaboration, and creative innovation do or don't develop when designers are managed by a designer who ascended through the ranks to a management position versus someone who attains this position who has been trained in solely in business. Additionally, several authors whose work was analyzed in this review addressed the fact that designers promoted to design managers don't necessarily also know how to manage projects or personnel (or budgets or client expectations), often because this is so rarely taught in design schools. ${ }^{38}$ While it is not the focus of the material examined across this review, it would likely be enlightening to examine whether one is truly a "better" manager of designers if one has accrued significant design experience. Whatever the possible findings of this type of investigation may be, these discussions indicate that university-level design educators need to prepare our students to be able to effectively communicate with managers who have not been to design school and who do not possess significant experience designing.

\section{Comparing Autonomous Versus Interventionary Approaches to the}

\section{Management of Design Processes in Professional Settings}

Another major factor that affects the creative management of designers in professional settings is the balance that often needs to be struck between allowing designers to work fairly autonomously and requiring them to be subject to fairly frequent interventions as their work progresses. Within the language of the 'creative climate,' this oppositional pairing is sometimes referred to by using 
39

Moultrie \& Young, “Exploratory Study of Organizational Creativity in Creative Organizations," 308.

40

Lawson, B. How Designers Think: The Design Process Demystified, Oxford: Elsevier-Architectural Press, 2006, p. 250.

41

Best, Design Management: Managing Design Strategy, Process and Implementation, 134. 42

Bilton, C. Management and Creativity: From Creative Industries to Creative Management. Malden, MA, USA:

Blackwell Publishing, 2007, 86.

43

Sunley, P., Pinch, S., \& Reimer, S. “Design Capital: Practice and Situated Learning in London Design Agencies." Transactions of the Institute of British Geographers, 36.3 (2011): pgs. 377-392. the terms freedom and idea support. ${ }^{39}$ In How Designers Think, ${ }^{40}$ Lawson points out that a key management decision involves determining how much autonomy to afford a given designer or design team during a specific creative process. Best couches her description of the need to time these interventions in a call for managers to better understand the importance of balancing a designer or design team's need for freedom with their need to focus. She opines that this requires thoughtful decisions to be made about when to allow space and time for divergent thinking and when to steer activities toward convergent thinking, all while balancing time, budget, and client needs. ${ }^{41}$ In Management and Creativity: From Creative Industries to Creative Management, Bilton also emphasizes the critical importance of how a manager should facilitate (or not) intervention. He calls for greater empathy to be forged between managers and creatives, and for the interventions to be treated as a type of carefully orchestrated balancing act between understanding when to release and control designers' activities as particular projects evolve. ${ }^{42}$

While the elucidation of how or when to intervene isn't explored or mentioned in much detail within these texts, we can at least understand that the timing of and approaches to intervention vary significantly among design managers. ${ }^{43}$ The understandings offered by these authors about how managerial decisions to facilitate or restrict their designers' relative autonomy are made can positively affect how design is taught. Using class time to model how different, project-specific variables affect managers' decisions regarding intervention - specifically, when, in what way(s), within what types of parameters can help students better understand this key aspect of the design management process. As design educators, we each comport ourselves in our classrooms according to a particular "educational style" that students could be made aware of that parallels a specific "managerial style." As we fall into or consciously chart and navigate particular patterns of planning and behavior as we teach, we, like design managers in professional settings, must make thoughtful decisions about when and how to intervene in our students' creative processes, and when not to. We are uniquely positioned to model adaptable, flexible managerial behavior, or not, all the while bearing in mind that our students learn from being exposed to both. Making our decisions regarding these types of intervention decisions transparent to our students can more effectively prepare them to enter professional settings wherein those who manage their activities will also have to do this (but often without the transparency). 


\section{Analyzing How Design Processes Are Affected By}

the Environment within which They Occus

Another emergent theme derived from an analysis of the literature is how the construction and embodiment of knowledge within professional design practices is affected by the physical and socio-cultural environment that surrounds the creative processes that occur within them. This became most evident when the review was guided by inquiries about how shared vocabularies were developed among creative teams in professional design settings, with particular emphasis on how collaborative relationships between team members were forged and sustained.

\section{The Importance of Developing Shared Vocabulary}

In What Designers Know, ${ }^{44}$ Lawson highlights the importance of how designers (he focuses on product design and architecture) communicate with each other, and his exploration of this led him to examine how shared vocabularies within given organizations develop as projects progress and as given design firms themselves evolve as cultural entities. Lawson states, “The evocativeness of words is the key. This connects to Schön's ${ }^{45}$ suggestion that experienced designers use design archetypes during their design process often in the form of very evocative words." ${ }^{46}$ The explicit suggestion here is that if design managers are going to be successful, they need to develop and use these types of vocabularies effectively, as well as also play an active role in the evolution of the conversations that nurture them. This critical observation relates to Boland

Lawson, B. What Designers Know, Oxford: Elsevier-Architectural Press, 2004, 89. 45

Schön, D. A. The Reflective Practitioner: How Professionals Think in Action. New York, NY, USA: Basic Books, 1983.

4.6

Lawson, What Designers Know, 92.

47

Boland, R. \& Collopy, F., eds. Managing as Designing. Stanford, CA, USA: Stanford University Press, 2004. 48 Ibid., 251 and Collopy's work ${ }^{47}$ that encourages managers of design projects to think more like designers, which requires them to examine, and, if necessary, alter the vocabulary they use when attempting to identify, frame and resolve given design problems. Management of the design process can be a matter of instilling norms and creating a common vocabulary to describe what is deemed good or successful design. Understanding this co-created language as a generator of the creative process becomes essential to the design researcher, and then, by extension, the design manager, because it must be understood organically by a whole group, rather than being solely developed by one individual who then unilaterally applies this top-down to the whole group. ${ }^{48}$

\section{Building and Sustaining Effective, Collaborative Relationships} in Professional Design Settings 
49

Banks et al., "Where the Art Is: Defining and Managing Creativity in New Media SMEs," 262.

50

Ibid.

51

Borja de Mozota, Design Management: Using Design to Build Brand

Value and Corporate Innovation, 194; Owens, S., "Visual Continuity and Innovation in Editorial Design Practice." In Design and Creativity: Policy, Management and Practice, edited by G. Julier and L. Moor, pgs. 191-204, New York, NY, USA: Berg, 2009.

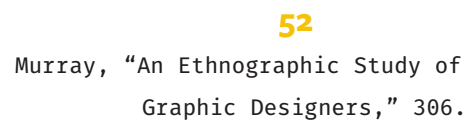
Graphic Designers," 306.

It is fairly essential for shared vocabularies to be co-created within and across a team - rather than having one mandated to them from above - if they are to collaborate effectively and work well together over time. In "Where the Art Is: Defining and Managing Creativity in New Media SMEs," the researchers reported that many graphic design managers seek to employ diversely populated and multi-skilled teams on complex, comprehensive visual communications projects because experience has taught them that these types of teams tend to produce more effective and more valuable design work. ${ }^{49}$ In the graphic design firms that were examined during this research, group-based creativity was emphasized, and it was determined that the most productive and effective teams worked in close proximity to each other, which helped to facilitate the free sharing of ideas. ${ }^{50}$ It was observed that ideas shared in this way helped fuel the development of shared language among team members, which coincidentally fueled the construction and free flow of knowledge created by team members and design managers in these creative environments. The work of other authors whose work was analyzed to inform this review supports these findings. A brief synopsis of these is articulated as follows:

Ibid.
In “An Ethnographic Study of Graphic Designers," Murray expands on the idea of the need for design professionals to develop and sustain use of shared vocabularies. She highlights the idea that when a professional graphic design environment is configured into an open, collaborative space which allows for the communal construction of knowledge, the vocabulary that develops within this space is also communally constructed. ${ }^{52}$ Graphic designers who work in these types of professional environments develop a shared working model and understanding of how their particular consultancy, firm or organization really works on a daily basis. As these processes evolve, individual designers come to better understand their roles within it, especially if they are situated in an open physical environment that allows them to observe each other as they work. ${ }^{53}$ (It should be noted that the creative process may transpire differently when individual graphic designers work by themselves in an otherwise communal environment, or work remotely, or in some other type of isolated environment. 
The studies examined in this review did not address these types of situations.) Graphic design educators can operationalize the knowledge on offer here by using it to guide how we configure the physical and social environments within which we prepare our students to enter the profession. It appears as if there is a considerable advantage to designing and maintaining classroom settings - both in their physical and online forms - that function to allow for open, collaborative dialogues to occur between students and faculty. The onus is on graphic design educators to make fostering the development of collaborative learning environments a priority, so that the useful types of knowledge constructed within them can be effectively nurtured and cultivated.

\section{Investigating Key Constraints Inhibiting the Creative}

\section{Process in Professional Graphic Design Environments}

A final, prominent aspect of this review is the array of critical descriptions and synposes offered by the authors about what they observed to be some of the leading constraints inhibiting the creative process in professional graphic design settings. Most professional designers are likely quite familiar with some of these through personal experience. They can arise from a poorly framed and/or crafted design brief (particularly if it is not informed by ethnographically gleaned understandings of key users, stakeholders or audiences), limitations imposed by time or budget, or confusing, inadequate or inappropriate client feedback. Constraints can and are also deliberately introduced by design managers and sometimes by clients or other project partners in an attempt to provoke creativity and guide the development of more innovative or-much more difficult-inventive design solutions. Creative outcomes to design processes are evaluated differently by different internal audiences within a given design firm: technical aspects of printed or digitized systems of visual communications are assessed by a production staff; the account staff focuses on ensuring that marketing efforts are guided by issues of focus specified by the client; management concerns itself with working within set budgets to create effective, valuable deliverables; designers focus on developing aesthetically compelling and conceptually viable design work. ${ }^{54}$ The array of studies examined in

54

Dorland, A. "Routinized Labor in the Graphic Design Studio." In Design and Creativity: Policy, Management and Practice, edited by $G$. Julier and L. Moor, pgs. 105-121, New York, NY, USA: Berg, 2009 this review provide valuable insights that help build understandings about how constraints imposed by each of these groups can be effectively leveraged to affect the management of design processes. For design educators, these understandings can be used to reinforce strategies and tactics that increase emerging 
55

Owens, "Visual Continuity and

Innovation in Editorial Design

Practice," 202.

56

Dorland, Routinized Labor in the Graphic Design Studio.

57

Julier, Economies of Design, 46. designers knowledge of how constraints can be leveraged to fuel innovative and creative thinking.

\section{Examining Constraints Rooted in Formal Design Issues}

The long-standing, graphic design studio model of introducing aesthetic constraints into given sets of design parameters (often still articulated in design briefs) continues to assert itself strongly in the professional graphic design workplace. The literature reviewed that informs this article indicates that some managers of design projects introduce constraints that are informed almost exclusively by aesthetic or formal concerns, such as color palette, use of particular styles of imagery, or typographic treatments of various text elements. In some cases, these managers have been shown to impose artificial limitations on themselves and/or the designers on the teams they manage in order to challenge conventional approaches and provoke more inventive solutions. ${ }^{55}$ In a study of editorial design departments, the researcher Sarah Owens describes a world that is regimented, routinized, and deadline-focused. Her argument is that the balance between repeated process and opportunities for inventive thought can be built into the creative process. She goes on to offer that they are complementary and need each other to exist to foster creative practice that yields desirable, valuable results. Deliberately interjecting these constraints into a high-paced work environment could be an effective strategy to retain and promote intrinsic motivation and engagement. Testing the veracity of this suggests a possible avenue for future research. Additionally, graphic design educators can use these ideas to guide their thinking about the design constraints that we interject into the classroom with an eye towards variability and a goal of helping students avoid unoriginal, shallowly informed and explored, "beenthere-done-that" design solutions.

\section{Analyzing Managerially Imposed Constraints}

In another recent ethnographic study of graphic designers titled "Routinized Labor in the Graphic Design Studio" published by AnneMarie Dorland, on-site ethnographic research at a Canadian design and branding firm was conducted. Dorland addressed the extensive auditing and management practices that regulate opportunities for creativity in these settings. ${ }^{56}$ Guy Julier expanded on this line of inquiry in his book Economies of Design when he stated that the two sides of design are commercial demands and creative autonomy, both of which are, "part of the necessary, rational activities of its economic work." ${ }^{57}$ In 
reality, there is less autonomy than one would think (or would be prescribed in a 'creative climate'), and it is a given graphic design firm's clearly articulated processes and procedures that will determine a designer's success in that environment. ${ }^{58}$

Both Dorland and Murray observed that when the managerially imposed constraint of limited time allotted to the generation of creative ideas per a given client project is in effect, designers look to extant, published sources of material designed by others or successful past solutions that they themselves have designed for quick inspiration. These solutions were not judged to be inferior; rather, they were described as simply being a routine part of the design process in those creative environments. In Murray's study, designers turned to image and design source books to generate ideas quickly within allotted turnaround times. ${ }^{59}$ Dorland pushes the examination of this issue of managerially imposed time and budget constraints further, highlighting the that these systematized processes are fundamentally part of the professional graphic design studio, shaping any and all creative work that gets generated. For many firms, profitability is the ultimate measure of success, rather than creativity or aesthetics. ${ }^{60} \mathrm{~A}$ designer Dorland interviewed acknowledged that this focus on profitability is not taught in design school, describing the daily professional reality of having to stop and move on before having the chance to fully develop a promising idea. ${ }^{61}$ Some professional graphic designers have developed strategies to deal with these limitations within their respective creative processes. As

Murray, "An Ethnographic Study of Graphic Designers," 301-302.

60

Dorland, "Routinized Labor in the Graphic Design Studio," 112.

61 Ibid., 113

62 Ibid., 116.

63

Banks et al., "Where the Art Is: Defining and Managing Creativity in New Media SMEs," 261. was the case in Murray's study, where professional graphic designers looked at design annuals (in print and online) and other extant sources of "award-winning design ideas," Dorland's study examines this method for generating ideas but expands it further. Her inquiries probe how these design professionals develop working formulae that have been shown to yield successful outcomes to similar sets of design parameters, as opposed to trying to invent radical new ideas each time. ${ }^{62}$ The Banks study indicated that, at larger advertising and marketing firms, managers were more likely to use constraints to limit the scope of their designer's creativity so that projects came in 'on time and on budget,' often at the expense of outcomes that some on the design staff had deemed more artistic or progressive. ${ }^{63}$ Banks' study also indicated that smaller graphic design firms tended to "take more creative risks," and valued their ability to do so. Smaller firms were shown to operate a looser, more facilitative managerial style compared to larger firms, where managers of design teams felt the need to instill and control a process whereby they had more control over 
64

Ibid.

65

Davis, "Raising the Bar for Higher Education," 16. (and could more effectively predict) creative output. ${ }^{64}$ This echoes Dorland's findings about the operation of managerial systems that are fundamental to many professional graphic design firms. In larger firms, it follows that more comprehensively organized, rigidly structured systems are needed to manage more people and the (generally more complex) projects that these types of firms take on. Conversely, the managers in smaller firms have a closer view of the day-to-day creative activity within the office, and, because of this, have the ability to apply and operate managerial approaches more flexibly on a per project basis.

Management and economic concerns shape the creative process more than many graphic design educators are willing to acknowledge, much less utilize as knowledge to inform how they design and facilitate at least some portions of their curricula. Using the understandings revealed in the studies that have been analyzed in this review should have a more a profound impact on how future graphic designers are educated. As stated previously in this piece, several notable American design educators (such as Davis, Poggenpohl, Wilde, and Buchanan, among many others) have called for the current generation of our peers to encourage designers to move beyond focusing on design as a means to generate formal artifacts and systems, and, in so doing, broaden the scope of professional practice. ${ }^{65}$ One key step in doing this effectively is to more overtly and explicitly include well-considered, non-formally focused constraints into the management of design processes so that they yield outcomes that are valued as being more than so called formal solutions. This is how design processes have begun to yield outcomes that change how organizations do things, how their cultures are structured, and how those they collaborate with might gain or even create new, useful knowledge. Part of this also encourages design educators to challenge their students to rely much less on 'occupational formulae' for creating their work — and learning to create their work - which may well allow them more opportunities to create work that results in more than mere artifacts. In short, emerging designers need learn how to meet deadlines and satisfy budget restrictions while also ideating in ways that yield original and appropriate design work, whether it is artifact-based or not. To achieve this, another revelation from Dorland's study needs to be emphasized: design educators need to become more effective at teaching students how to communicate to different constituencies - managers, fellow designers, clients, and vendors - in order to be successful. 


\section{Conclusion}

More research is needed that investigates and examines the management of the creative process at graphic design firms, especially in light of the fact that so much of what they are now being called upon to deliver as outcomes of their creative processes is not strictly rooted in artifact creation. While there is a lack of scholarly literature that focuses specifically on analyzing management strategies and tactics of graphic design firms, there are a few key ethnographically framed examples; however, the sample sizes of the firms studied in these are quite small. In addition, previous authors have highlighted the importance of social, physical and cultural context on the operation of creative practices in a given professional setting, and that therefore what creativity means within any given firm is highly context specific. Additionally, factors such as the practitioners' own understanding/negotiation of creativity and their perceptions of the practices operating across their profession affect this significantly. ${ }^{66}$

This review uncovered two other future tracks of inquiry that could warrant further inquiry and reflection. One is to expand the review of the management of creative processes in other industries and then investigate how these might be effectively applied within professional graphic design practices. There is a substantial amount of scholarly literature about the study of managing creativity in ways that include the fostering of innovative practices. Another line of inquiry from the research delves into how designers think and practice in order to better understand how the design process can be better managed. This could be connected to the many different interpretations of 'design thinking,' as well as Cross' examination of 'designerly ways of knowing,' ${ }^{67}$ which can help us learn more about the designer's thought process and how it might be managed most effectively in professional and academic settings.

Finally, it is vital that attempts to understand this process further be undertaken, so that those who prepare future professional designers to sustain their careers can connect what is learned to our pedagogical approaches in graphic design education. Future inquiries could help us to better understand how we teach and manage the creative process of our students in order to

66

Banks et al., "Where the Art Is: Defining and Managing Creativity in New Media SMEs," 262. 67 Cross, N. "Designerly Ways of Knowing." Design Studies, 3.4 (1982): pgs. 221-227. align these more with the reality of what is occurring and will occur in professional practices. Seizing upon the idea of introducing constraints into the design management of creative processes in professional environments: design educators need to move beyond merely framing the challenges we assign our students with (mostly) aesthetically rooted constraints, and include client-imposed and firm/consultancy-imposed constraints. As we do this, we must also 
be cognizant of preventing students from relying too quickly on 'occupational formulae' that lead to repetitive, non-innovative solutions to design problems.

The design education community must reflect on its use of collaboration across its diversely populated landscape, and work to more effectively build a shared vocabulary. (One way of doing this is for a broad cross section of American design educators to participate in the soon-to-be-created "Graphic Design Teaching Resource," which was being constructed as this piece was being written in July 2017 by Annabelle Gould of the University of Washington at Seattle and which is supported by an AIGA "Innovate" Grant.)

Are our students becoming skilled collaborators? What kind of facilitation do they respond to most effectively as their creative processes evolve? Are they able to effectively process critique and feedback in order to generate more creative solutions? Can they clearly communicate with different constituencies? Future research is needed to better understand the practice of managing creativity in professional graphic design firms, and then how knowledge gleaned from this might best be embedded into the curricula and daily approaches to teaching in American graphic design education programs. The need to develop this endeavor further is also evinced throughout this examination of the existing literature about managing creative processes, as not enough students are entering the profession with even rudimentary understandings of how creative processes are managed in professional settings.

\section{References}

Amabile, T. Creativity in Context: Update to the Social Psychology of Creativity. Boulder, CO, USA: Westview Press, 1996.

Banks, M., Calvey, D., Owen, J., \& Russell, D. “Where the Art Is: Defining and Managing Creativity in New Media SMEs." Creativity and Innovation Management, 11.4 (2002): pgs. 255-264.

Best, K. Design Management: Managing Design Strategy, Process and Implementation. London, UK: Bloomsbury, 2015.

Best, K. The Fundamentals of Design Management. Lausanne, Switzerland: AVA Publishing, 2010.

Bilton, C. Management and Creativity: From Creative Industries to Creative Management. Malden, MA, USA: Blackwell Publishing, 2007.

Boland, R. \& Collopy, F. Managing as Designing. Stanford, CA, USA: Stanford 
University Press, 2004.

Borja de Mozota, B. Design Management: Using Design to Build Brand Value and

Corporate Innovation. New York, NY, USA: Allworth Press, 2003.

Cooper, R., Junginger, S., \& Lockwood, T., eds. The Handbook of Design Management. London, Uk: Bloomsbury, 2013.

Cross, N. "Designerly Ways of Knowing." Design Studies, 3.4 (1982): pgs. 221-227.

Davis, M. "Raising the Bar for Higher Education," in The Education of a Graphic Designer, edited by S. Heller, pgs. 13-18, New York, NY, USA: Allworth Press, 2005 .

Dorland, A. "Routinized Labour in the Graphic Design Studio.” In Design and Creativity: Policy, Management and Practice, edited by G. Julier and L. Moor, pgs. 105-121. New York, NY, USA: Berg, 2009.

Dorst, K. \& Cross, N. “Creativity in the Design Process: Co-evolution of Problem-Solution.” Design Studies, 22.5 (2001): pgs. 425-437.

Ekvall, G. “Organizational Climate for Creativity and Innovation.” European Journal of Work and Organizational Psychology, 5.1 (1996): pgs. 105-123.

Grant, D. "Special Business Degrees Mark Shift From Making Art to Managing It," The Chronicle of Higher Education, February 9, 2011. Online. Available at: http://www.chronicle.com/blogs/arts/special-businessdegrees-mark-shift-from-making-art-to-managing-it/28613. Accessed June 28, 2017.

Jacobs, J. “Teaching the Business of Design Across Disciplines.” The International Journal of Design Education, 10.2 (2016): pgs. 19-29.

Julier, G. Economies of Design. London, UK: Sage Publications, 2017.

Lawson, B. How Designers Think: The Design Process Demystified. London, UK: Routledge, 2006.

Lawson, B. What Designers Know. London, Uk: Routledge, 2012.

Moultrie, J. \& Young, A. "Exploratory Study of Organizational Creativity in Creative Organizations." Creativity and Innovation Management, 18.4 (2009): pgs. 299-314.

Murray, D. "An Ethnographic Study of Graphic Designers," in Proceedings of the Third European Conference on Computer-Supported Cooperative Work, 13-17 September 1993, Milan, Italy, Dordrecht, The Netherlands: Kluwer Academic Publishers, 1993: pgs. 295-309.

Oakley, M., Borja de Mozota, B. \& Clipson C., eds. Design Management: A Handbook of Issues and Methods. Cambridge, MA, USA: Blackwell Reference, 1990. 
Owens, K. M. \& Gibson, M. R. “It's Time to Stir the Pot...” Dialectic, 1.1 (2016): pgs. 5-8.

Owens, S., "Visual Continuity and Innovation in Editorial Design Practice." In Design and Creativity: Policy, Management and Practice, edited by G. Julier and L. Moor, pgs. 191-204. New York, NY, USA: Berg, 2009.

Schön, D. A. The Reflective Practitioner: How Professionals Think in Action. New York, NY, USA: Basic Books, 1983.

Sunley, P., Pinch, S., \& Reimer, S. “Design Capital: Practice and Situated Learning in London Design Agencies." Transactions of the Institute of British Geographers, 36.3 (2011): pgs. 377-392.

Von Stamm, B. Managing Innovation, Design and Creativity. West Sussex, UK: John Wiley \& Sons, 2008.

Walker, D. “Managers and Designers: Two Tribes at War?” in Design Management, edited by M. Oakley, B. Borja de Mozota, \& C. Clipson, pgs. 145154. Cambridge, MA, USA: Blackwell Reference, 1990.

“What is Design Management?” Design Management Institute. Online. Available at: http://www.dmi.org/?What_is_Design_Manag. Accessed June 24, 2017.

\section{Biography}

Jessica Jacobs is an Assistant Professor in the Business \& Entrepreneurship Department at Columbia College Chicago where she teaches classes in design management, entrepreneurship, and project management. Jessica's crossdisciplinary research interests and professional endeavors revolve around design management pedagogy, arts and design entrepreneurship, and synergies between art and business utilizing methods and language from the creative process. She has presented, exhibited and published her scholarly and creative work nationally and internationally and recently received a 2017 AIGA Design Educators Community Faculty Research Grant for her project, "Understanding Best Practices in Student-Operated, Faculty-Advised Campus Design Studios.” Jessica received a BS from Northwestern University and an MFA from Savannah College of Art and Design. (jjacobs@colum.edu, jessicajacobs.com) 